\title{
Experimental Study on Flexural Capacity of Reinforced Concrete Beam after Collision
}

\author{
GuangHui Wang ${ }^{1,2}$, XiaoYan Liu ${ }^{1, *}$, ChengLong Wei ${ }^{1}$, Zhenhao Zhang ${ }^{1,3}$ and WeiWei Wang ${ }^{2}$ \\ ${ }^{1}$ School of Civil Engineering and Architecture, Changsha University of Science and Technology, Changsha, 410076, China; \\ ${ }^{2}$ The College of Civil Engineering and Architecture, Hunan Institute of Science and Technology, Yueyang, 414000, China; \\ ${ }^{3}$ Civil engineering department, College of engineering, University of Alaska Anchorage, Anchorage AK, MI 99508, USA
}

Received 19 October 2016; Accepted 15 February 2017

\begin{abstract}
The residual load-bearing capacity of a reinforced concrete (RC) beam with collision damage was studied based on the loading test and theoretical analysis of the damaged beam to determine whether the damaged RC beam bridge after truck collision, could continue to be used and reveal the mechanical properties of the damaged beam. First, an experiment was conducted on the RC beam after truck collision to obtain material parameters. The nonlinear finite element models of two experimental beams were then corrected according to experimental results, based on which the experimental schemes of the damaged beam were designed and its loading test was performed. Finally, according to the experimental and finite element calculation results, the concept of damage coefficient was adopted and the calculation methods for the flexural capacity of the damaged beam were proposed. Research results indicate that the normal section failure at the midspan of the damaged RC beam arises from the edge position of the damaged region. The upper concrete on the section of the damaged part is crushed under the failure. The normal section bearing capacity of the damaged beam is slightly lower than that of the undamaged beam. The short-term flexural capacity of the damaged beam can be determined by the $5 \%$ decreasing bearing capacity of the undamaged beam only when the concrete in the tensile region is damaged after collision. The bearing capacities of the damage beam may be determined by the calculation formula for rebar damage when they are cracked. This research provides the theoretical and experimental foundations for the evaluation of the technical state of the RC bridges after collision.
\end{abstract}

Keywords: Bridge engineering, Vehicle-bridge collision, Damaged beam, Flexural capacity, Loading test

\section{Introduction}

In recent years, China has built many overpasses and flyovers to address traffic jam problems. Collision accidents between over-height vehicles and the main beams of overpasses and flyovers frequently happen because of the carelessness and negligence of drivers and the inefficient management of these bridges by the road and bridge maintenance department [1,2]. After vehicles have collided with the bridge superstructure, the concrete of the main beam is crushed and the rebar is fractured in less serious cases, and the beam falls in more serious cases. The bridge administrative department should evaluate the technical state I of beams that have experienced collisions to ensure structural safety. According to the Chinese Evaluation Standard of Bridge Technical State [3], bridges that have experienced collisions can be directly classified as Class V bridges in terms of danger and must be demolished and reconstructed. Whether these damaged bridges should be demolished or reconstructed, what the actual ultimate bearing capacity is, and whether these damaged bridges can be used are problems that are worth exploring. Therefore, bearing capacity test must be conducted on damaged bridges after collisions. Consequently, the establishment of the

E-mail address: xiaoyanliu2003@126.com

ISSN: 1791-2377 @ 2017 Eastern Macedonia and Thrace Institute of Technology. All rights reserved. calculation formula for the ultimate bearing capacity of damaged reinforced concrete (RC) beams has become an urgent concern in the evaluation of the technical state of damaged beams.

This study focused on the failure modes and ultimate bearing capacity of damaged beams after collision based on the destructive test and the theoretical analysis of RC beams. The mechanical properties and failure modes of damaged and undamaged beams were discussed from the experimental mechanics perspective. Moreover, the principle of damage mechanics was used to establish a calculation model for the flexural capacity of damaged beams based on elastic-plastic mechanics.

\section{State-of-the-art}

Collision accidents between over-height vehicles and bridge superstructures occur frequently [1,2]. Many scholars have studied the collision between vehicles and bridges [4-10], and their research has focused on the dynamic response, impact force, collision failure mode, and evaluation of technical state during the collision process. However, few studies on the bearing capacity of damaged RC bridges after collision exist. Reference [11] studied the bearing capacity of bridges with which vehicles had collided based on the damage theory, used the finite element software ABAQUS to simulate the mechanical response and the bearing capacity 
problems of bridges that were hit by vehicles at different speeds and from different angles, and adopted an average damage degree parameter to correct the concrete strength and calculate the bearing capacity of damaged beams.

| Reference [12] took a bridge that had been hit by a vehicle as the study object, used an ultrasonic pulse method to detect the thickness of the damaged surface layer, and evaluated the bridge after collision through the thickness data of the damaged surface layer that was measured when detecting the region that was hit and the squeeze and scratch position at the beam bottom. Reference [13] conducted a destructive test of a bridge that was to be demolished in America, and the test results indicated that the degrading material properties ruined the multi-aspect bridge properties significantly, especially the ultimate bearing capacity. Reference [14] took a steel truss bridge as the engineering background and carried out a research on the influence of local damage on its structure. References [15] and [16] studied the identification methods of bridge damage. Reference [17] conducted the field detection and lab model test of a multi-span railway bridge, based on which the influence of damage on the structure was studied. Reference [18] performed the destructive loading test of a single Ibeam of a bridge and conducted a dynamic test during the loading process; cracking occurred after the load test, and the natural frequency of the vibration of various test points decreased as the load continuously increased. Reference [19] used four methods to evaluate the bearing capacity of a damaged bridge, and the evaluation results obtained by different methods were contradictory. However, the final destructive test indicated that the calibration coefficients obtained through the evaluation of the damaged beams might be incorrect, which would reduce resistance excessively and result in wrong evaluation conclusions. Reference [20] implemented a destructive test of a RC simple support T-beam bridge, which served for 43 years in Ningxiang County, Hunan Province, whose failure mode was a typical flexural structural failure with yielded tensile steel bars and crushed concrete.

Previous studies mainly concentrated on the evaluation of the technical state of the bridges that had been hit, and their evaluation results should still be discussed. Few studies have been conducted on the residual load-bearing capacity of damaged RC beams after collision. Many scholars have conducted experimental studies on the residual load-bearing capacity of damaged structures. These research achievements are significant in determining the relationships between the flexural capacity of damaged bridges and the damage degrees and positions. However, they cannot be directly applied to the calculation of the bearing capacity of damaged bridges after collisions. Therefore, a RC bridge that was cracked by an excavator was taken as the research

I object. Two main beams (one was seriously damaged and the other was basically undamaged) on the bridge were selected. Destructive tests in relation to the basic principles of nonlinear mechanics were conducted on the damaged and undamaged beams, based on which an analysis was performed and a calculation model of the damaged beam was built. The model was built to identify the influence of the damage degree of the RC beam's midspan tensile zone on its flexural capacity.

The rest of this paper is organized as follows. Section three describes the damage status of the RC beam and establishes its bearing capacity analysis model, based on which a destructive test of two RC beams was conducted. Section four analyzes the failure modes and the load- deflection curves of the damaged beam and studies the calculation methods of the flexural capacity of damaged beams through numerical simulation. The final section summarizes this study and offers relevant conclusions.

\section{Methodology}

\subsection{General situation of the experiment}

A two-hole 13-m RC I-beam flyover in Yueyang, Hunan Province was built in 1995 with a designed load of vehicle15. The bridge superstructure is five I-beams. In December 2014, a truck carrying an excavator (the total weight of which was about $20 \mathrm{t}$ ) passed under the bridge. The long arm of the excavator was not placed as it should be required, When the truck passed below the bridge, the long arm of the excavator collided with the bottom of the main bridge beam. Several main beams were seriously damaged, as shown in Fig. 1.

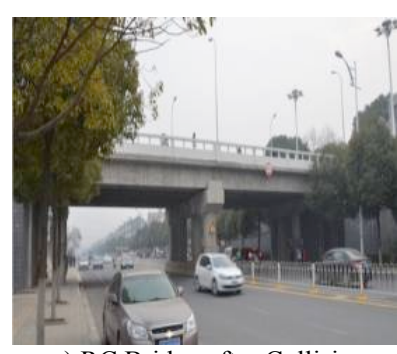

a) RC Bridge after Collision

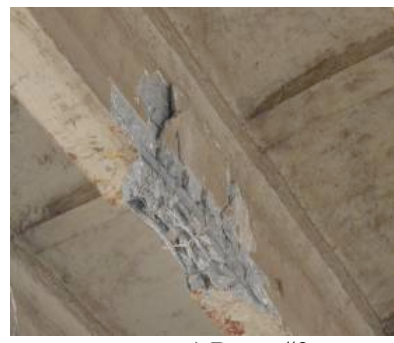

c) Beam \#2

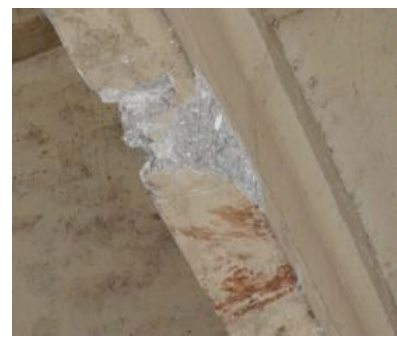

e) Beam \#4

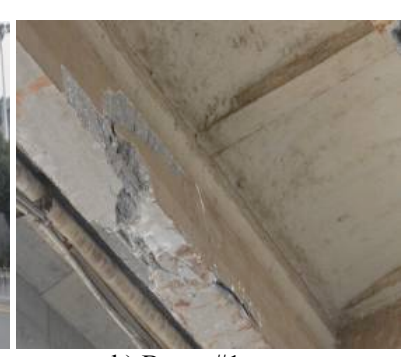

b) Beam \#1

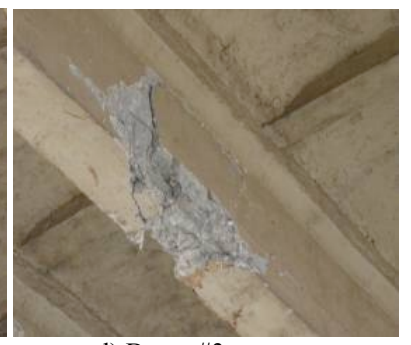

d) Beam \#3

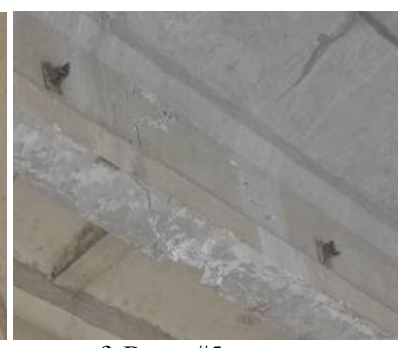

f) Beam \#5
Fig. 1. RC Bridge and Beams after Collision

Fig.1 shows that with five beams damaged, beam \#2 sustained the most serious damage, followed by beam \#3. The protective layer of beam \#4 was cracked. Therefore, considering bridge demolition safety, beam \#3 and \#4 were demolished and transported to the lab for an experiment. Grids with $10-\mathrm{cm}$ spaces were drawn with ink lines on the surfaces at two sides of the beams (Fig. 2) to measure the damage of the beam accurately and observe the cracks during the follow-up loading test. The state of damaged beam \#3 section is shown in Fig. 3. 


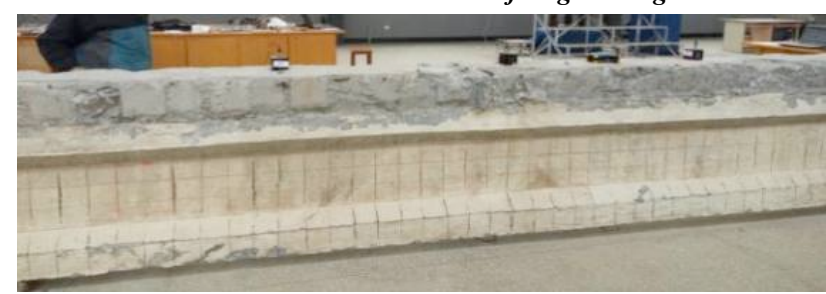

Fig. 2. Grid Lines for Observation of Main Beam Cracks

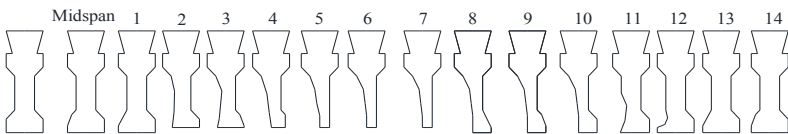

Fig. 3. State of Damaged Beam Section

\subsubsection{Rebar scanning}

The rebar positions inside the beams were confirmed through the rebar scanning tests of the two beams (Fig. 4).

\subsubsection{Concrete strength test}

An ultrasonic-rebound combined method was used to determine the concrete strength of the tested beams. Ten measuring zones were uniformly distributed on the damaged beam (Fig. 5). A rebound test was conducted, and an ultrasonic wave test was implemented. The strength of each measuring zone was calculated by combining the results of the rebound and ultrasonic wave tests (Tab. 1).

\subsection{Conventional measurement}

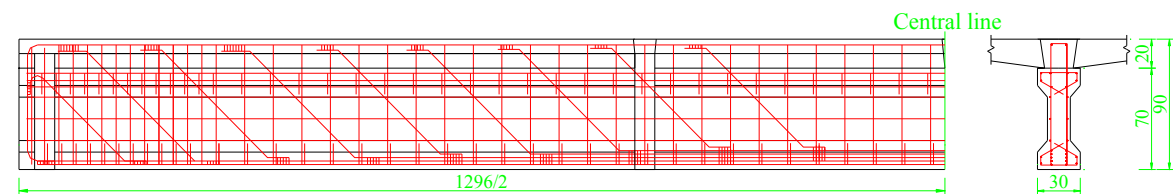

Fig. 4. Reinforcement Drawing of Test Beam

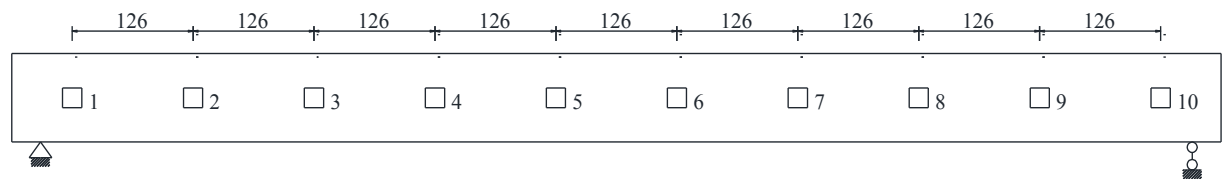

Fig. 5. Schematic Diagram of Measuring Zone Arrangement (Unit: cm)

Table 1. Strength Presumption

\begin{tabular}{c|cccccccccccc}
\hline Measuring zone & 1 & 2 & 3 & 4 & 5 & 6 & 7 & 8 & 9 \\
\hline Strength coversion value (Mpa) & 45.9 & 50.1 & 33.6 & 40.3 & 39.3 & 37.3 & 42.4 & 30.1 & 27.8 & 25.0 \\
\hline
\end{tabular}

\subsection{Finite element analysis}

The measuring results from the previous stage were used to establish finite element analysis models (Figs. 6 and 7). The models showed that concrete adopting an elastic-plasticdamage constitutive model had a good bonding with the rebar, for which an elastic-plastic constitutive model was adopted, and the conquassation of concrete in the compressive zone was taken as a criterion for model damage, as shown in Fig. 8. Concrete was simulated with a solid element and rebar was simulated with a bar element.

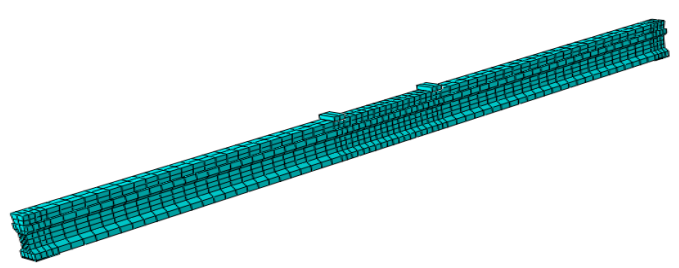

Fig. 6. Finite Element Model of Undamaged Beam

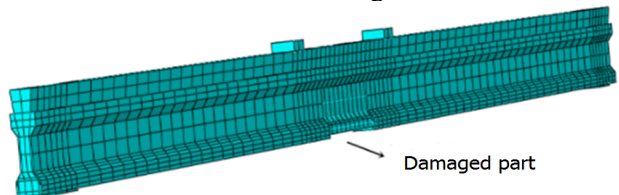

Fig. 7. Finite Element Model of Damaged Beam

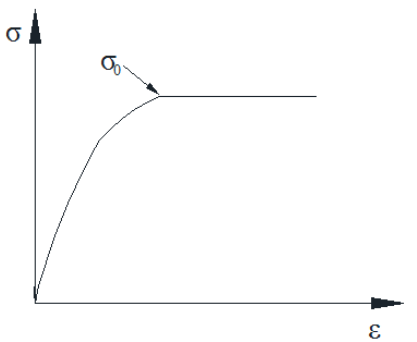

a) Compressive Constitutive Relation of Undamaged Beam

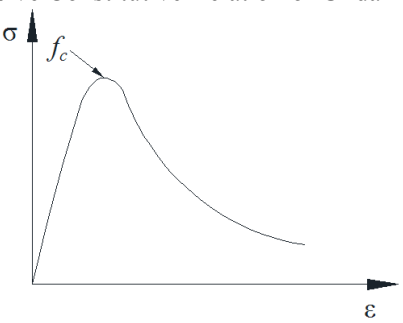

b) Compressive Constitutive Relation of Damaged Beam

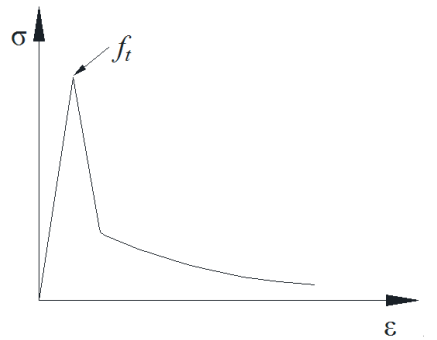

c) Tensile Constitutive Relation of Concrete 
GuangHui Wang, XiaoYan Liu, ChengLong Wei, Zhenhao Zhang and WeiWei Wang/

Journal of Engineering Science and Technology Review 10 (1) (2017) 114 - 122

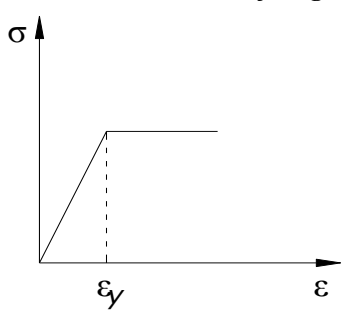

d) Constitutive Model of Rebar

Fig. 8. Constitutive Models of Concrete and Rebar

\subsection{Experimental scheme}

\subsubsection{Loading scheme}

Finite element calculation results indicated that, in addition to the dead load, the undamaged beam could also bear an $899-k N . m$ bending moment. Considering the differences between the calculation model and the true situation of the structure, the experimental loading system could apply a $1244.6-k N . m$ bending moment to the beam, and reservation for a $345-k N . m$ bending moment still existed based on the theoretical calculation results.

Specific loading measures are shown in Fig. 9. A distributive beam was set below an actuator, and supports (one fixed support and one movable support) were set symmetrically at the two ends of the distributive beam. During loading, the actuator implemented single-point loading, and the load was transferred to the main beam through the distributive beam.

\subsubsection{Test scheme}

A total of 18 deflection measuring points and 76 strain measuring points were arranged in the test to reflect the actual mechanical properties of the test beam under the effect of load. The concrete arrangement scheme of measuring points are as follows:

1) Deflection was measured with two sets of systems, electronic displacement meter and level gauge, which were simultaneously used and implemented mutual calibration. Deflection measuring points were set at eight equant segments on the tested beam. The deflection measuring points were arranged as measuring points 1-9 in Fig. 10.

2) The strain was measured with two sets of systems, the strain gauge and the vibrating wire strainmeter, which were simultaneously used in the test and implemented mutual calibration. The bridge has been used for years. Thus, strain rosettes were set in positions which were $10 \mathrm{~cm}$ away from the support and equivalent to the beam height and $1 / 4$ of the section, to prevent the recessive damage of some unknown parts from the changing failure mode of the structure. Strain measuring points in the axial direction of the beam were set in positions, namely, the midspan section, the collision section, and the load-bearing rebar, as shown in Figs. 11 and 12.

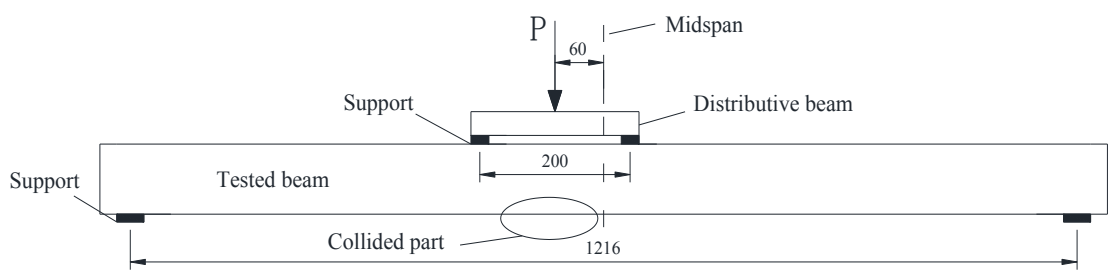

Fig. 9. Loading Diagram (Unit: $\mathrm{cm}$ )

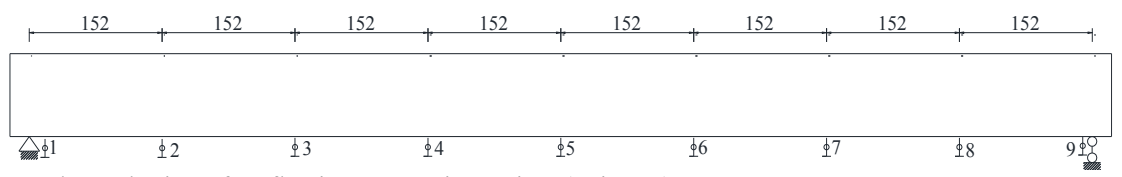

Fig. 10. Arrangement and Numbering of Deflection Measuring Points (unit: $\mathrm{cm}$ )

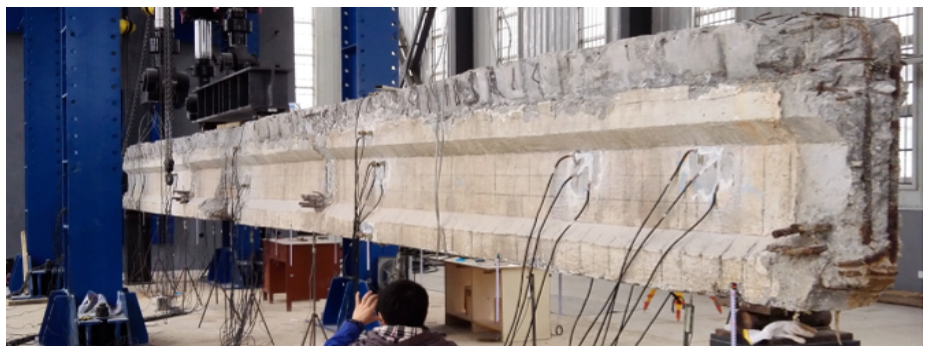

Fig. 11. Strain Measuring Point Arrangement of Damaged Beam

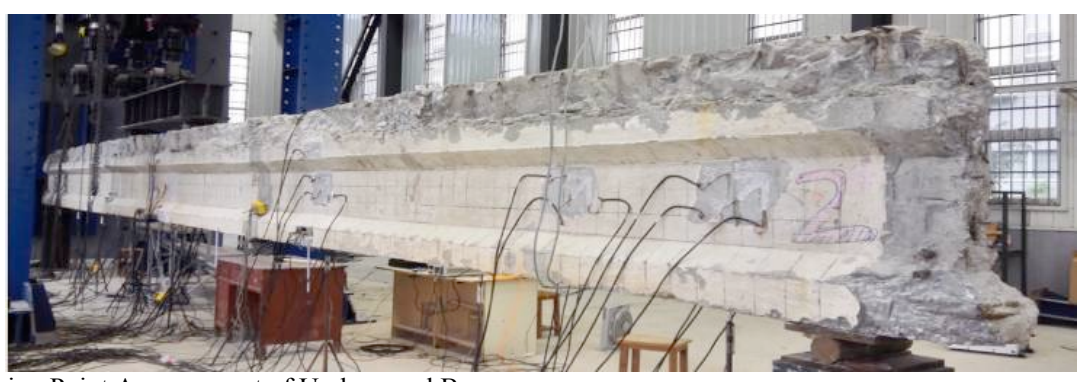

Fig. 12. Strain Measuring Point Arrangement of Undamaged Beam 


\section{Results and discussion}

\subsection{Experimental process and phenomenon}

Through finite element calculation, the ultimate load of the damaged beam was $400 k N$ and that of the undamaged beam was $403 k N$, showing a minor difference in the ultimate load. This test used multi-stage loading, with an initial load of $20 \mathrm{kN} /$ stage. After the test load reached 380 $k N$, the densified load was $10 \mathrm{kN} /$ stage. When 430 $k N$ was reached, displacement control of the loading was implemented until the beam was completely damaged. Fifteen-min pre-loading was implemented to check whether the equipment was operating normally. The pre-loading size was $20 \%(80 \mathrm{kN})$ of the calculated theoretical value of the ultimate load. When load was added to $200 \mathrm{kN}$, the first visible crack appeared beside the damaged section that was hit. New cracks appeared in each stage while original cracks expanded. The lower edge of the midspan section mostly had vertical cracks, and the $1 / 4$ section nearby mostly had diagonal cracks. When the load increased, multiple cracks near the midspan ran through the beam bottom and extended to a neutral axis zone that surrounded the damaged section to form a run-through crack. The deflection increment of the main beam increased significantly at the load of $360 \mathrm{kN}$. At the load of $400 \mathrm{kN}$, one rebar at the beam bottom yielded, and then the other rebars successively yielded, and the cracks in the damaged section of the main beam continuously expanded and extended upward. At the load of $430 \mathrm{kN}$, tensile failure occurred at the main reinforcing bar. The concrete in the compressive zone was crushed, and the main beam reached its ultimate bearing capacity. The cracks in the undamaged beam started from the midspan section and expanded toward the two ends. As the load increased, cracks continuously appeared and developed until the tensile rebar yielded and the compressive concrete was crushed. The bearing capacity of the undamaged beam was slightly higher than that of the damaged beam.

\subsection{Deformation and rigidity of test beam}

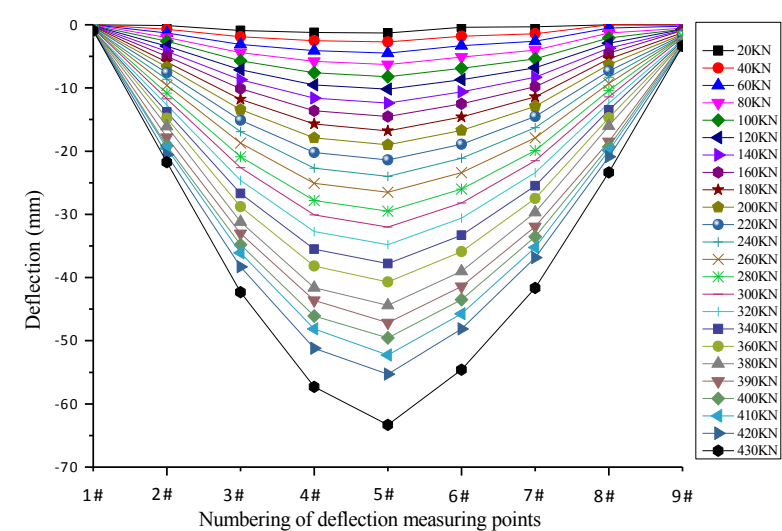

Fig. 13. Deflection of Damaged Beam under Effect of Multi-Stage Load

Fig. 13 shows that the deflection of measuring point $4 \#$ (3L/8 section) near the collision position of the main beam was larger than that of measuring point $6 \#$ ( $5 \mathrm{~L} / 8$ section), which indicated that the damage affected the local beam deflection. After $360 \mathrm{kN}$ was loaded, the changing rate of deflection increased, which indicated that the main beam rigidity rapidly decreased and entered the plastic state. The ultimate load of the damaged beam was approximately 430 $k N$, and the maximum deflection of the midspan deflection position was approximately $65 \mathrm{~mm}$.

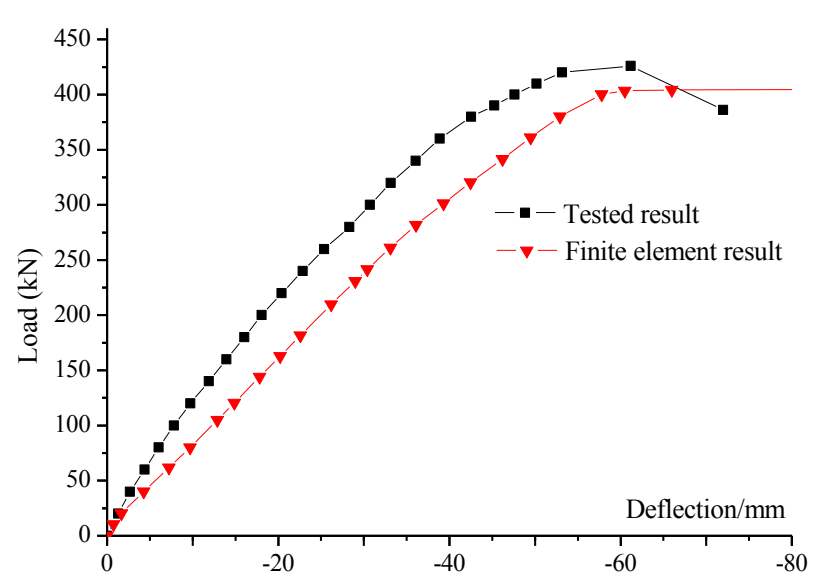

Fig. 14. Comparison Chart of Load-Deflection Curves of Damaged Beam

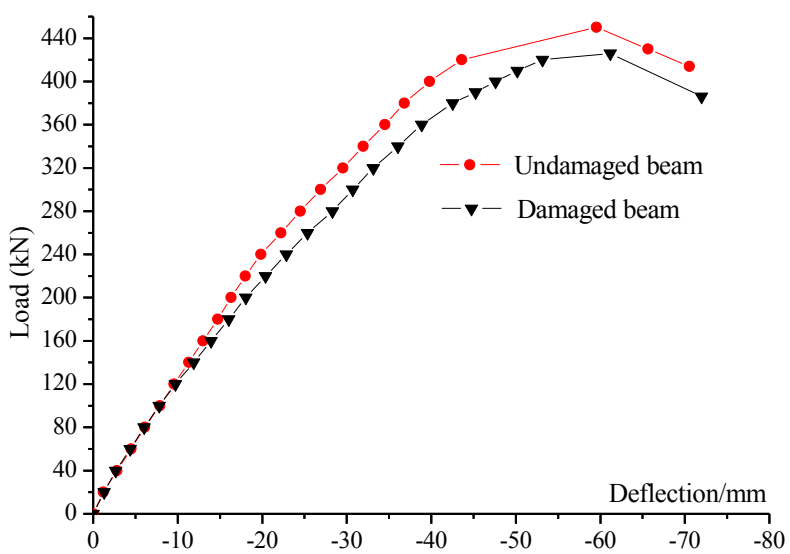

Fig. 15. Comparative Curves of Measured Load-Deflection Values of Midspan Section

The comparison between the load-deflection test curves and the finite element analysis result of the midspan section is shown in Fig. 14. The theoretical deformation value of the damaged beam was greater than the measured value in the test when loading was implemented. Thus, the rigidity of the finite element model was smaller than the actual rigidity of the tested beam. The difference between the theoretical and measured values reached the maximum at $360 \mathrm{kN}$. One rebar at the beam bottom yielded with the increasing growth rate of the test value, which exceeded that of the analytical value. The tested deformation was approximate to the calculated deformation after the concrete in the compressive zone was crushed. Moreover, no obvious linear segment appeared in the initial loading stage on the load-deflection curve of the damaged beam. Thus, no elastic phase appeared in the initial loading phase of the RC beam because of the damage.

A comparison between the damaged and undamaged beams through the load-deflection test curves of the midspan section is shown in Fig. 15. During the loading process, the deformation of the damaged beam under the same load was greater than the deformation of the undamaged beam because the beam damage reduced its rigidity. However, for the ultimate load, the deflection of the damaged beam was basically identical with that of the 
undamaged beam. The ultimate load of the damaged beam was $430 \mathrm{kN}$, and that of the undamaged beam was $440 \mathrm{kN}$. Thus, the ultimate load of the undamaged beam was slightly higher than that of the damaged beam by $2.3 \%$, which indicated that the concrete damage in the tensile zone in the midspan region had minimal influence on the bearing capacity, thus verifying that concrete strength might not be considered in the concrete structural calculation. Moreover, in the initial loading phase, an obvious linear segment on the load-deflection curves of the undamaged beam existed but not on the load-deflection curves of the damaged beam.

\subsection{Concrete and rebar strain}

For the damaged beam, the strain distributions at the $1 / 4$, midspan, and $3 / 4$ sections along the beam depth are shown in Figs. 16-18.

Figs. 16 and 18 show that the strain distributions at the $1 / 4$ and $3 / 4$ sections of the damaged beam along the beam depth were basically consistent with the plane-section assumption, but the maximum tensile strains of the two sections were not at the beam bottom because the concrete on the lower section in the midspan region loosened after the collision and stress redistribution occurred at the beam bottom, which reduced the stress of concrete on the lower $1 / 4$ and $3 / 4$ sections to a certain degree. Fig. 17 shows that the lower strain on the midspan section was small and the concrete strain in the tensile zone did not conform to the plane-section assumption because of the influence of concrete loosening and "rounding" cracks at the edges of the damaged section. This part of concrete mainly exited from the operation. Fig. 19 indicated that the concrete strain in the compressive zone of the midspan section and the rebar strain in the tensile zone were consistent with the plane-section assumption.

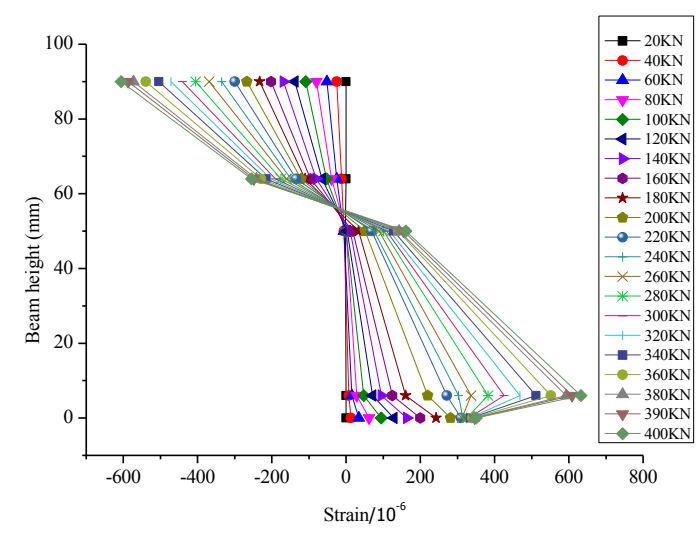

Fig. 16. Concrete Strain Value of the $1 / 4$ Section

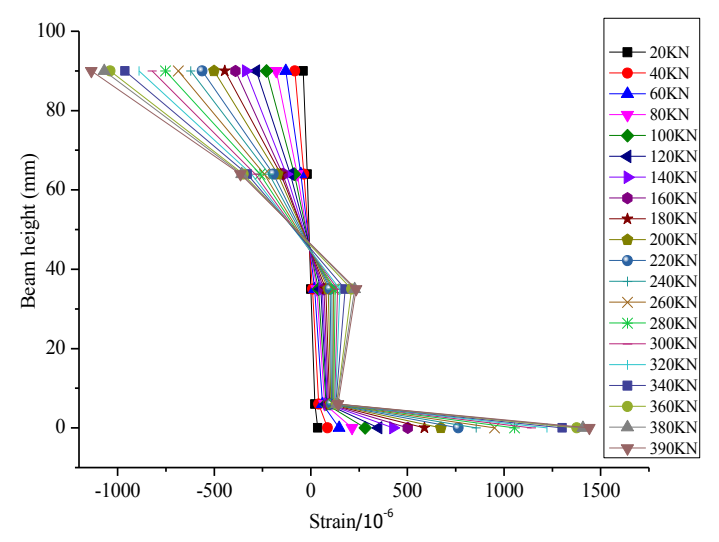

Fig. 17. Concrete Strain of the Midspan Section

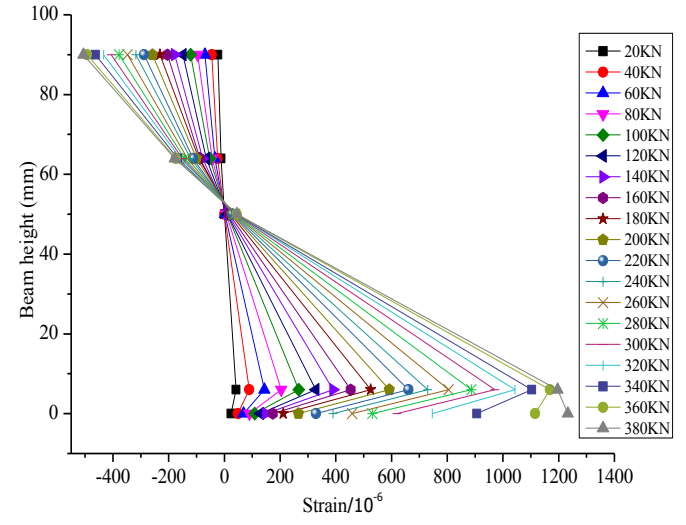

Fig. 18. Concrete Strain of the $3 / 4$ Section

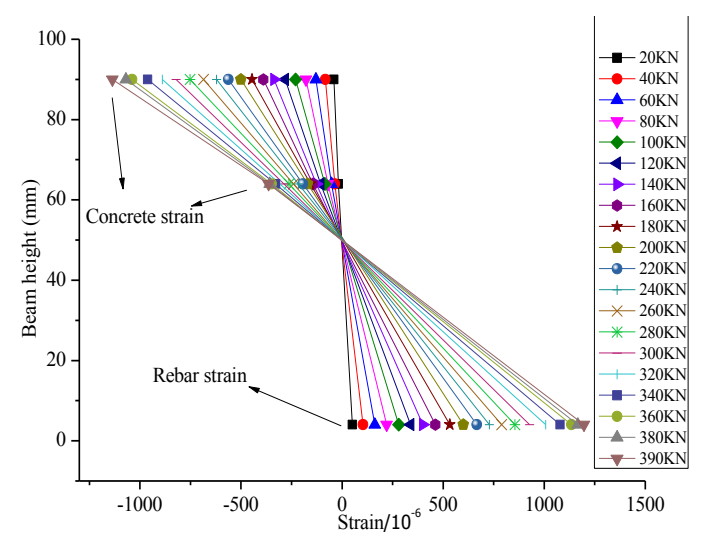

Fig. 19. Concrete and Rebar Strains of the Midspan Section

The comparison of the concrete strain curves of the damaged and undamaged beams is shown in Fig. 20.

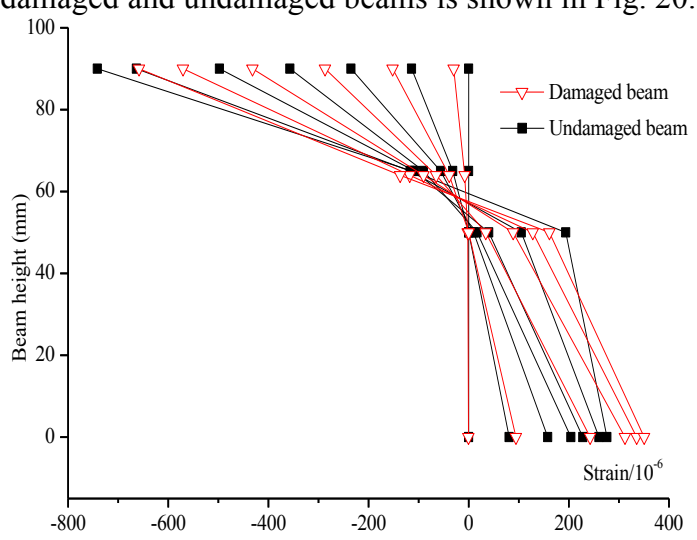

a) $1 / 4$ Section

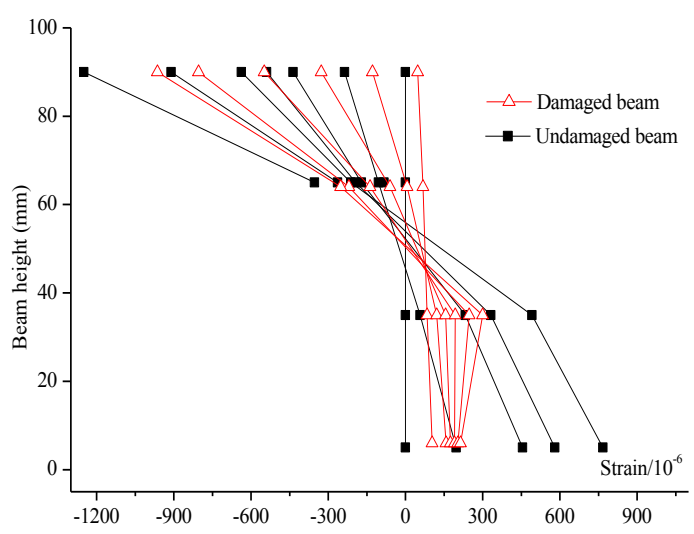

b) Midspan Section 


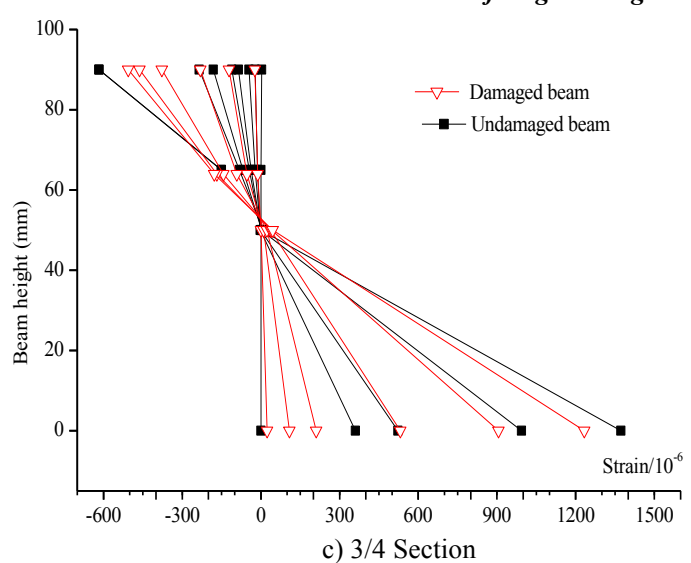

Fig. 20. Comparison Diagram of Concrete Strain of Various Sections

Fig. 20 shows a $1 / 4$ section close to the collision region and the damaged $1 / 2$ section. The strain in the tensile zone did not agree with the plane-section assumption. The strain in the $3 / 4$ section, which was far from the collision section, presented a linear distribution along the beam depth, while the strain in the tensile zone was obviously large. The concrete tensile strain value for the midspan section of the damaged beam was approximately zero. The concrete exited from the operation, and the concrete strain in the compressive zone maintained a linear distribution.

\subsection{Cracks and failure mode}

When $400 \mathrm{kN}$ was loaded, the strain of rebar $1 \#$ at the beam bottom steeply increased, and the rebars successively yielded. The cracks in the damaged section continuously expanded and extended upward, and the cracks in other parts also expanded continuously. When the strain was $430 \mathrm{kN}$, the concrete in the compressive zone of the damaged section was crushed (Fig. 21). The crack on the damaged section of the main beam developed into the position running through the neutral axis and one yielded rebar going through the tensile failure (Fig. 22). The cracks in the test beam are shown in Fig. 23, which indicates that the test beam reached the limit state of the bearing capacity, and the failure mode of the damaged beam was a typical under-reinforced failure. The prior failure of the damaged section further indicated that the damaged section was a weak section of the component.

Fig. 21. Top Concrete is Crushed
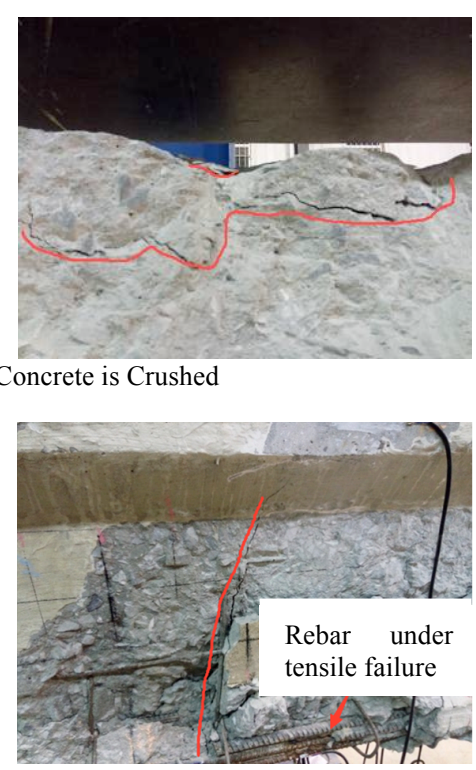

Fig. 22. Cracks on the Damaged Section Expanded

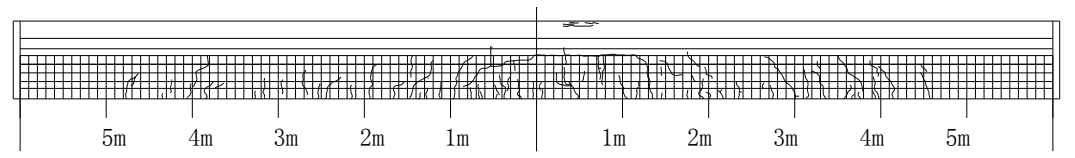

Fig. 23. Crack Distribution Graph of Main Beam

\subsection{Calculation formula for the bearing capacity of the damaged beam after collision}

The finite element calculation results of the damaged beam and the ultimate bearing capacity test simultaneously indicated that the collision part had minimal influence on the normal section bearing capacity when in the tensile zone of the beam. Moreover, the failure mode of the RC beam was still an under-reinforced beam failure. The bearing capacity $M_{\mathrm{u} 1}$ of the damaged beam after collision should be analyzed from two perspectives. First, the concrete in the tensile zone was damaged, and the tensile rebar was not broken by the collision. Second, the concrete in the tensile zone was damaged, and the tensile rebar was broken by the collision.

\subsubsection{Tensile rebar is not broken by collision}

Reference [12] proposed the method of importing damage coefficient $D_{c}$ to correct the bearing capacity calculation formula of the RC beam. For the damaged beam to be tested, the area damage coefficient of the maximum damaged concrete section was $D_{\mathrm{c}}=0.25$, and the flexural capacity of the damaged beam would decrease by $25 \%$. However, it only decreased by $2.3 \%$ in the test, and the decrease ratio in the finite element calculation result did not reach $1 \%$. Thus, this formula is inappropriate for the flexural capacity calculation of the concrete-damaged beam in the tensile zone at the midspan section. According to the test results, the finite element model was corrected, based on which a finite element model with $0 \%-70 \%$ concrete damage in the tensile zone and $10 \%$ concrete damage in the compressive zone in the midspan region was established. The flexural capacity was calculated and analyzed.

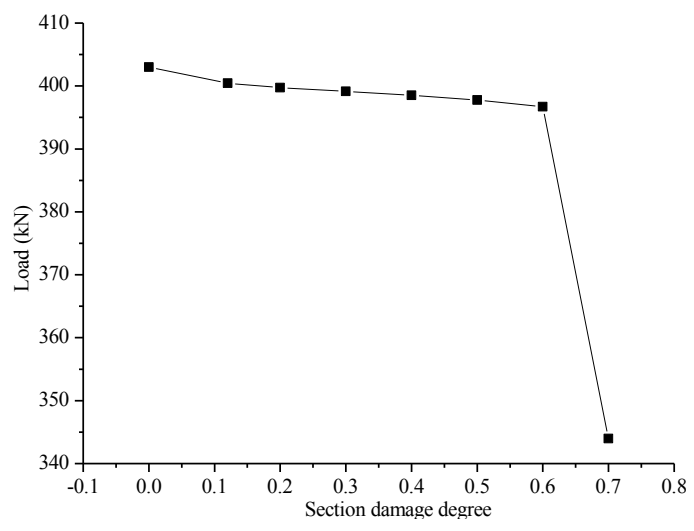




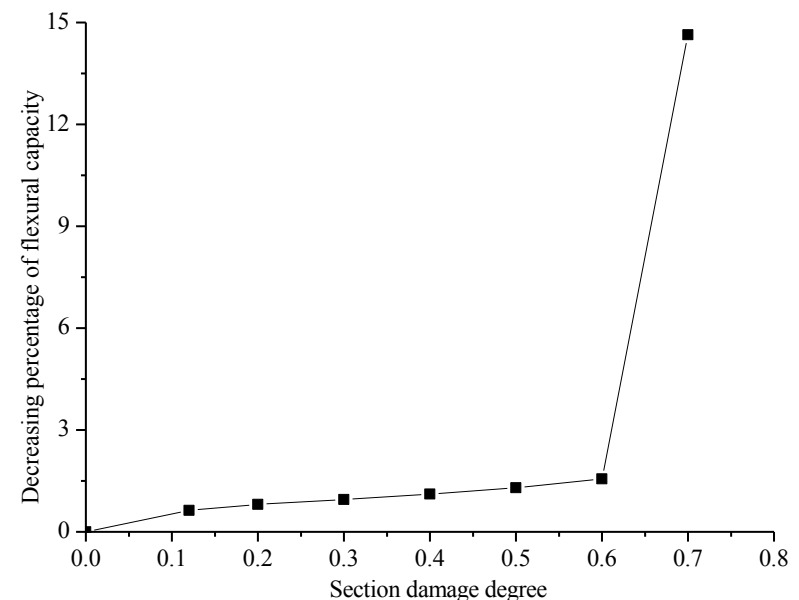

Fig. 24. Relation Curves between Flexural Capacity and Concrete Damage Degree in the Tensile Zone

The relation curves between the flexural capacity of the $\mathrm{RC}$ and the concrete damage in the sectional tensile zone (Fig. 24) indicated that the ultimate flexural capacity decreased slightly when the cross-sectional damage degree was smaller than 0.6. Therefore, the normal section calculation of the $\mathrm{RC}$ component did not consider the contribution of concrete to tensile resistance in the tensile zone. When the damage degree reached 0.7 , the flexural capacity sharply decreased because cross-sectional damage entered the compressive zone. Therefore, the degree of decrease of the short-term flexural capacity brought by the concrete damage in the tensile zone could be $5 \%$ when the $\mathrm{RC}$ beam was damaged by collision, provided that the upper edge of the damaged position did not exceed the neutral axis.

The concrete in the tensile zone of the main beam would be damaged by truck collision easily. However, the case of only the concrete damage by truck collision in the tensile zone is rare. The model calculation indicated that concrete damage in the compressive zone had a significant influence on flexural capacity. The decrease ratio of ultimate flexural capacity reached $14 \%$ when the concrete in the compressive zone damaged $10 \%$ of the whole section.

\section{4..2 Tensile rebar is broken by collision}

The flexural capacity calculation formula of the RC beam, as provided by Code for Design of Highway Reinforced Concrete and Prestressed Concrete Bridges and Culverts, is as follows.

$$
M_{\mathrm{u}}=f_{s d} A_{s}\left(h_{0}-x / 2\right)
$$

where $h_{0}$ is the effective height of the section, $x$ is the calculated depth of the compressive zone, $x=\frac{f_{\mathrm{sd}} A_{\mathrm{s}}}{f_{\mathrm{cd}} b}, f_{\mathrm{sd}}$ is the design value of the tensile strength of the longitudinal tensile rebar, and $A_{\mathrm{s}}$ is the cross-sectional area of the longitudinal tensile rebar.

Thus, after the tensile rebar was broken by collision, its area and flexural capacity decreased. Therefore, the rebar damage coefficient, $D_{\mathrm{s}}=\frac{A_{\mathrm{ss}}}{A_{\mathrm{s}}}$, was imported, and $A_{\mathrm{ss}}$ was the broken area of the tensile rebar. Flexural capacity $M_{\text {us }}$ can be calculated by the following formula:

$$
M_{\mathrm{us}}=f_{s d}\left(1-D_{\mathrm{s}}\right) A_{s}\left(h_{0}-x / 2\right)
$$

The accuracy of Formula (2) was verified by building six models with tensile rebar area losses of $0.00,0.08,0.17$, $0.25,0.33$, and 0.41 , to calculate the flexural capacity. These models simultaneously considered concrete damage, as shown in Tab. 2.

Table 2. Comparison of Bearing Capacities Calculated with Two Methods

\begin{tabular}{c|c|c|c}
\hline $\begin{array}{c}\text { Damage } \\
\text { coefficient }\end{array}$ & $\begin{array}{c}\text { Calculation result of formula in this study } M_{u s} \\
(k N \cdot m)\end{array}$ & $\begin{array}{c}\text { Finite element calculation result } M_{F} \\
(k N \cdot m)\end{array}$ & $\begin{array}{c}\text { Difference ratio } \\
M_{u s}-M_{F}\end{array}\left|M_{u s}\right|$ \\
\hline 0.00 & 830.08 & 843.28 & $1.59 \%$ \\
0.08 & 779.74 & 782.32 & $0.33 \%$ \\
0.17 & 726.12 & 726.44 & $0.04 \%$ \\
0.25 & 669.24 & 665.48 & $0.56 \%$ \\
0.33 & 609.08 & 594.36 & $2.42 \%$ \\
0.41 & 545.66 & 528.32 & $3.18 \%$ \\
\hline
\end{tabular}

Tab. 2. indicates that the bearing capacity of the RC beam rapidly decreased as the quantity of the damaged rebars increased. The bearing capacity calculated by a finite element was consistent with that after the damage coefficient was imported. Therefore, the bearing capacity correction calculation formula with the imported damage coefficient could be applied in engineering.

Moreover, normal section bearing capacity could be calculated by the under-reinforced beam when the quantity of broken main rebars under tension is large and when the residual effective area is smaller than the required minimum reinforcement ratio.

\section{Conclusion}

An experimental study of damaged RC beams after truck collision was conducted to address the evaluation problems on the technical state of RC bridges with main beams that have been damaged by truck collision and to improve the utilization rate of damaged bridges. The whole load-bearing process of the damaged beams was analyzed starting from the bearing capacity test of the damaged main beam of the RC bridge after excavator collision. Nonlinear calculation and the analysis model of the damaged RC beam were established based on the basic nonlinear finite element principle. Finally, the following conclusions were drawn. 
1) The ultimate flexural capacity of damaged beams is slightly lower than that of undamaged beams. The loaddeflection curve of damaged beams directly enters the plastic state in the initial phase. The failure of damaged beams mainly presents the tensile failure of main rebars and crushed concrete in the compressive zone, and the failure mode is the under-reinforced beam failure.

2) The concrete strain near the damaged region is not consistent with the plane-section assumption, but the concrete strain in the compressive zone and rebar strain in the tensile zone on the same section are.

3) In actual engineering application, the degree of decrease of the normal section flexural capacity is calculated as $5 \%$ when only concrete is damaged, provided that the upper edge of the damaged region of the section does not exceed the neutral axis. Normal section flexural capacity can be calculated according to the formula proposed in this study if the rebars are broken by collision.

This study proposed the calculation formula for the bearing capacity of damaged RC beams after truck collision based on engineering practice and theoretical study. This study is of great realistic significance to improving the accuracy of the technical evaluation of damaged beams and taking full advantage of damaged bridges. Flexural capacity is related to collision position in addition to being related to the damage degree of RC beams. Therefore, future studies should build a nonlinear finite element calculation model of damaged RC beams in different positions to study the relationship between the collision position and the flexural capacity of RC beams.

\section{Acknowledgments}

This work was supported by the National Basic Research Program of China 973 Plan (project no. 2015CB057701), the Youth Program of the Ministry of Education of Hunan Province (project no. 12B056), the Science and Technology Planning Project of Changsha (project no. K1309003-11) and the Research Project of Hunan Institute of Science and Technology(project no. 2015Y07).

This is an Open Access article distributed under the terms of the Creative Commons Attribution Licence

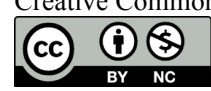

\section{References}

1. LU Xinzheng, ZHANG Yansheng,Ye Lieping and He Shuitao, "Failure modes and load calculation of collision between over-high truck and bridge superstructure". China Journal of Highway and Transport, 22(5), 2009, pp:60-67.

2. LU Xinzheng, LU Xiao, ZHANG Yansheng and HE Shuitao, "Engineering Calculation Method for Collision Force between Overheight Truck and Bridge Superstructure ". China Journal of Highway and Transport, 24(2), 2011, pp:49-55.

3. The ministry of transport highway research institute, "Standards for Technical Condition Evaluation of Highway Bridges". China Communications Press, 2011.

4. S El-Tawil, E Severino and P Fonseca, "Vehicle Collision with Bridge Piers". Journal of Bridge Engineering, 10(3), 2005, pp:345-353.

5. University of Maryland study, "vehicle collision with highway bridges". Maryland State Highway Administration Final Report Contract, No.SP907B1, 2001.

6. Reseach and technology bureau annual report of highway division, "highway research and development in Iowa". Annual Report, 2004,12.

7. Abdullatif, K. Zaouk, Nabih E. Bedewi, Cing-Dao Kan and Dhafer Marzougui, "Validation of anon-linear finite element vehicle model using multiple impact data. American Society of mechanical Engineers". Applied Mechanics Division, 1996, 218:91-106.

8. Ma Xianglu, "Dynamic response analysis of overpass bridge funder superelevation vehicles' collision". Beijin University of technology,2009. 9. Fu C, Burhouse J and Chang G-L, "Overheight Vehicle Vollisions with Highway Bridges". Transportation Research Record: Journal of the Transportation Research Board, 2004, pp:80-88.

10. LIU Fei, "Analysis and Investigation of Recent Bridge Accidents". Central South University, 2014.

11. BAO X and LI B, "Residual Strength of Blast Damaged Reinforced
Concrete Columns". International journal of impact engineering, 37(1), 2010, pp:295-308.

12. Ma Jicheng, "Study on the Calculation Method of the Bearing Capacity of Damaged Beam Bridges". Chang an University, 2010.

13. R.A.Miller, "Destructive Testing of Decommissioned Concrete Slab Bridge”. Joural of Structural Engineering. 120(7), 1994, pp:21762198.

14. G Brunell and YJ Kim, "Effect of local damage on the behavior of a laboratory-scale steel truss bridge". Engineering Structures, 48, 2013 , pp:281-291.

15. ZW Chen, S Zhu, YL Xu, Q Li and QL Cai, "Damage Detection in Long Suspension Bridges Using Stress Influence Lines". Journal of Bridge Engineering, 20(3), 2014, pp:05014013.

16. HW Shenton and X Hu, "Damage identification based on dead load redistribution: methodology". Journal of Structural Engineering, 132(8), 2006, pp:1254-1263.

17. N Domede, A Sellier and T Stablon, "Structural analysis of a multispan railway masonry bridge combining in situ observations, laboratory tests and damage modelling”. Engineering Structures, 56, 2013, pp:837849.

18. Qu Erren, Xia Xiaomei, Yin Yonggao, Ma Junhai and Zhang Jinghua, "Experimental research on the bearing capability of single beam for Bainianhe Bridge in Hefei-Anqing Freeway". Journal Of Hefei University Of Technology. 24(3), 2001, pp.345-349.

19. Shu Guoming and Shang Xinhong, "Research on ultimate bearing capacity evaluation of bridge beam based on entity destructive test". Highway, 10(7), 2010,.pp:54-59.

20. Peng Hui, Zhang Jian-Ren, Zhang Ke-Bo and Hao Hai-Xia, "Experimental study of ultimate behavior of existing bridge using destructive testing”. Engineering mechanics. 28(7), 2011,.pp:186-195. 